\title{
GRANULOSA CELL TUMOR OF THE ADULT TESTIS. REPORT OF A CASE AND REVIEW OF THE LITERATURE
}

\author{
Marcelo Hisano, Frederico Mota Mascarenhas Souza, Denise Maria Avancini \\ Costa Malheiros, Antonio Carlos Lima Pompeo, and Antonio Marmo Lucon
}

Testicular neoplasms are diseases that can arise from germ cells, sex cord, or stroma. Neoplasms originating from the latter two represent $4 \%$ of cases. ${ }^{1,2}$ Of the neoplasms derived from the sex cord, granulosa cell tumor of the adult testis is extremely rare, and its biological behavior is unclear. $^{2,3}$

A 59-year-old man, referred to us with a 2-year history of a painless growing mass in the left testis without past history of trauma, infection, or lower urinary tract symptoms. Physical exams revealed a normal right epididymis and testis, and a 13-cm mass and hydrocele in the left testis, without hernia. Ultrasonography showed a 15 x 11 x $12 \mathrm{~cm}$ mass with solid and cystic components and a large hydrocele. Serum levels of alpha-fetoprotein, beta-hCG, and $\mathrm{LDH}$ were within normal ranges. He underwent inguinal surgical exploration of the left testis in October 2000, when a large testicular mass was found. A radical orchiectomy was performed, and the hydrocele fluid was analyzed. No frozen section biopsy was performed. Histopathological examination showed a 9-cm yellow tumor, with a small degenerated cystic area. Final analysis revealed a granulosa cell tumor with oval nuclei having a longitudinal nuclear groove (coffee bean appearance - Figure 1), focal invasion of the tunica albuginea and rete testis, no mitotic figures, and no invasion of surgical margins, spermatic cord, or epididymis. Cytological analysis of the hydrocele fluid was negative for tumor cells. Immunohistochemical tests were positive for vimentin, actin HFN 35, desmin, and cytokeratin AE-1/AE-3, but negative for epi-

Department of Urology, São Paulo University Medical School, São Paulo/ SP, Brazil.

Email: marcelo.hisano@sbu.org.br

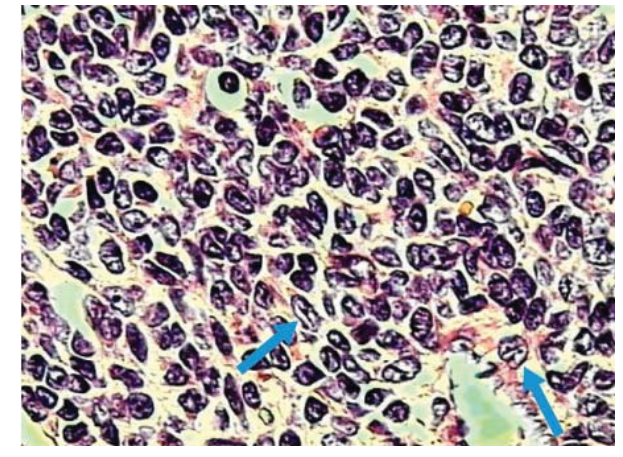

Figure - Granulosa tumor cell: oval nuclei cells with longitudinal grooves (coffee bean aspect) - arrows

thelial membrane antigen. These findings strongly suggest the diagnosis of a granulosa cell tumor.

Follow-up was carried out with determinations of serum levels of alpha-fetoprotein, beta-hCG, and $\mathrm{LDH}$, as well as computerized tomography of the abdomen and chest x-ray every 6 months for 4 years, with no clinical recurrence or exam abnormalities.

Described for the first time in $1952,{ }^{4}$ granulosa cell tumors are derived from epithelial elements of the sex cord, and they can be divided in juvenile or adult types. ${ }^{1,2}$ The juvenile type is one of the most common congenital testicular tumor, and it occurs mostly in children younger than 1 year of age. The adult type is extremely rare, with only 21 cases reported in English language literature, ${ }^{1-3}$ and the youngest patient reported was 16 years old at presentation. ${ }^{1,5}$

Granulosa cell tumors affect mainly white males, usually as a painless testicular mass. ${ }^{5,6}$ Gynecomastia is present in $25 \%$ of cases, ${ }^{3,5,7}$ due to hormonal abnormalities such as estrogen hypersecretion, or chromosomal abnormalities. ${ }^{1-3}$ Previous cryptorchidism has been reported in 2 cases. ${ }^{4,8}$ 
Histologically, these tumors resemble granulosa cell tumors of the ovary and may present in a variety of histological patterns such as solid, cystic, microfollicular, gyriform, insular, or trabecular. In the microfollicular presentation, cells may exhibit pseudo-acinar patterns surrounding nuclear fragments (the so-called Call-Exner bodies). ${ }^{1,2}$ Typically, neoplastic cells have oval nuclei with a longitudinal groove, in a "coffee bean" appearance. Diagnosis of this tumor from frozen section biopsy may fail, because it can mimic lymphoma. ${ }^{2}$ Immunohistochemical tests can aid the diagnosis. Usually, there is a strong reaction for vimentin, which occurred in this case, but variable results for cytokeratins, and negative tests for epithelial membrane antigen. ${ }^{1,3}$ Estrogen and progesterone receptors can also be helpful in the diagnosis because they are expressed in this neoplasm. ${ }^{6}{ }^{6}$ Bidart $^{10}$ suggests that immunostaining with mullerian inhibiting substance can be useful for distinguishing between granulosa and Leydig cell tumors. Mesenchymal differentiation into osteoid and smooth muscle components associated with this neoplasm has been described. ${ }^{3}$

The clinical behavior of these tumors is usually benign and indolent, but it is sometimes unpredictable, and 4 malignant cases have been described. ${ }^{1,3}$ Jimenez-Quintero, ${ }^{5}$ analyzing 7 cases, the largest series, suggests a long-term follow-up, because this is a slow-growing neoplasm that can potentially cause distant metastasis, even several years after initial presentation. It is generally believed that ovarian tumors have a worse prognosis than testicular ones. ${ }^{2}$ Histological features that suggest malignancy are as follows: tumor greater than 7 centimeters, increased mitotic activity, necrosis, and lymphovascular invasion. ${ }^{1,2}$ In the present case, even though the tumor was 9 centimeters in length, we did not find other malignant features, and the clinical behavior has been benign so far.

Ultrasonography can add more information and can be helpful in the differential diagnosis. The neoplasm can appear as a hypoechoic mass with few internal echoes. The juvenile type has been described as having a "swiss cheese" ultrasonographic appearance with solid and cystic areas. ${ }^{8}$

The usual age at which this neoplasm occurs is less than in this case, with only 2 cases reported in the sixth decade of life or later. ${ }^{3,5}$ In this decade of life, lymphomas and spermatocytic seminomas are the most common tumors, but sex cord tumors, mainly granulosa cell, deserve much attention since these tumors do not necessarily follow the predictable behavior of the germ cells tumors. The duration and periodicity of follow-up are still not well defined because biological behavior is unpredictable, and there are no characteristics of the primary tumor that predict its evolution. Because of its rarity, there is no independent factor that can predict prognosis. A systematic review of the cases that have already been described, with all their variables, might be helpful for establishing a histological score that could predict biological behavior.

In summary, granulosa cell tumors of the adult testes are rare diseases, and precise clinical and pathological diagnosis is important for guiding treatment decisions. Follow-up must be long due to their slow growth, malignant potential, and the absence of clinical or histological scores that can predict their biological behavior.

\section{REFERENCES}

1. Cheville JC. Classification and pathology of testicular germ cell and sex cord-stromal tumors. Urol Clin North Am. 1999;26:595-609.

2. Wang BY, Rabinowitz DS, Granato RC, Unger PD. Gonadal tumor with granulosa cell tumor features in an adult testis. Ann. Diagn Pathol. 2002;6:56-60.

3. Al-Bozom IA, El-Faqih SR, Hassan SH, El-Tiraifi AE, Talic RF. Granulosa cell tumor of the adult type: a case report and review of the literature of a very rare testicular tumor. Arch Pathol Lab Med. 2000; $124: 1525-8$.

4. Laskowski J. Feminizing tumors of the testis: general review with case report of granulosa cell tumor of testis. Endokcrinol Pol. 1952;3:33743.

5. Jimenez-Quintero LP, Ro JY, Zavalo-Pomba A. Granulosa cell tumor of the adult testis: a clinicopathologic study of seven cases and a review of the literature. Hum Pathol. 1993;24:1120-6.
6. Nistal M, Lazaro R, Garcia J, Paniagua R. Testicular granulosa cell tumor of the adult type. Arch Pathol Lab Med. 1992;116:284-7.

7. Matoska J, Ondrus O, Talerman A. Malignant granulosa cell tumor of the testis associated gynecomastia and long survival. Cancer. 1992;69:1769-72.

8. Gaylis FD, August C, Yeldandi A, Nemcek A, Garnett J. Granulosa cell tumor of the adult testis: ultrastructural and ultrasonographic characteristics. J Urol. 1989;141:126-7.

9. Due W, Dieckmann KP, Niedobitek G: Testicular sex cord stromal tumor with granulosa cell differentiation: detection of steroid hormone receptors as a possible basis for tumor development and therapeutic management. J Clin Pathol. 1990;43:732-7.

10. Rey R, Venara M, Jaubert F, Zeller WP, Chemes H, Bidart JM, et al. Anti-mullerian hormone is a specific marker of Sertoli and granulosa cell origin in gonadal tumors. Hum Pathol. 2000;31:1202-8. 